\title{
Survival as medical registrar on call: remember the doughnut
}

\author{
Authors: Sarah Blayney, ${ }^{\mathrm{A}}$ Alexander Crowe $^{\mathrm{B}}$ and Dominic Bray ${ }^{\mathrm{C}}$
}

Life as a medical registrar presents many challenges and concern is growing that a downwards trend in recruitment to General Medicine is the direct result of a perception by junior doctors that the role of the medical registrar is excessively demanding and results in poor work-life balance. A solutionfocused approach (SFA) can be used successfully to find a satisfying outcome for both registrar and patient in many of the situations encountered during an on-call, as well as carrying over benefits into life outside of work. We explore the origins of SFA and the ways in which it can be successfully applied to clinical medicine, providing case studies from the author's own experience to illustrate the principles of this way of thinking.

KEYWORDS: Medical registrar, satisfaction, general medicine, work-life balance, patient centred

Being the on-call medical registrar is a tough job; various reasons for this are well documented in the recent RCP report The medical registrar: Empowering the unsung heroes of patient care. ${ }^{1}$ It is a role that requires concentration, resilience and stamina, in addition to highly tuned clinical skills and decisiveness. Consequently the job can be both highly satisfying and intensely stressful, and demands a good deal of self-awareness. Concern is growing that a downward trend in recruitment to general medicine is the direct result of a perception by junior doctors that the role of the medical registrar is excessively demanding and results in a poor work-life balance. ${ }^{2}$

A solution-focused approach (SFA) ${ }^{3}$ can be used successfully to find a satisfying outcome for both registrar and patient in many of the situations encountered during an on-call session. It can be used to shape our own behaviour, as well as being applied to interactions with patients, and in this way can become a mechanism for coping with the bigger picture of life as a medical registrar. The first steps are to establish the patient's 'best hopes' for how the future will look. Establishing a patient's current strengths towards achieving that future provides the direction in which to look: aiming to do more of what already works. In a similar way, recognising trends in our behaviour allows us to reinforce good habits and develop further insight into what may or may not be helpful.

Authors: ${ }^{\text {A }}$ medical registrar in stroke and geriatric medicine, Geriatric Medicine, Southport \& Ormskirk District General Hospital, Southport, UK; ${ }^{\mathrm{B}}$ consultant renal physician, Wirral University Teaching Hospital, Wirral, UK; C Consultant clinical psychologist, Southport \& Ormskirk District General Hospital, Southport, UK

\section{What is a solution-focused approach?}

'Solution-focused brief therapy' was a concept developed in the 1980 s by a group of psychotherapists based in Milwaukee, Wisconsin, USA. ${ }^{4}$ Since then it has evolved further and become widely used throughout North America, Europe and Asia. ${ }^{5}$ It stemmed from the idea that a positive focus on existing strengths in order to find solutions was more efficient than lengthy analysis of deficits and problems, as had been the case with traditional psychotherapy. ${ }^{6}$ Since then it has gained popularity in many settings, including business and education, and the most recent systematic qualitative review $^{7}$ has shown significantly positive benefits across a number of fields including adult mental health, occupational health, and health and ageing. Of particular interest to hospital clinicians today are the promising results seen in chronic disease groups, including those with diabetes, ${ }^{8}$ Crohn's disease ${ }^{9}$ and dementia. ${ }^{10}$ As the evidence base has grown, so too has the number of comprehensive handbooks providing greater explanatory depth and conversation transcripts, to which we would direct interested readers. ${ }^{11,12}$ In Table 1 there is a summary of key techniques ${ }^{6}$ that can be used in clinical medicine, grouped loosely by principle. The baseline assumption is that the answer lies with the patient and so the role of the clinician is to facilitate this, offering medicine as a tool to support the patient in achieving his or her desired goal.

\section{How does a solution-focused approach work in clinical medicine?}

'Remember the doughnut' is an easy way to visualise and understand the solution-focused approach. This reminds us to focus on what is current rather than looking at deficits, eg the 'hole'. Instead of getting stuck on insolvable problems or treatment failures, attention is redirected to positive elements of the situation and their further development. This promotes a greater feeling of control for the patient because the subtle shift in attitude allows them to make constructive behavioural change with self-perpetuating positive feedback.

A patient's 'best hopes' may not align with those of the doctor responsible for his or her management, and there may be friction due to differing views on what the priorities of treatment should be. This can lead to significant anxiety and a challenge to the confidence of both patient and doctor. Establishing patient preference has been proposed by the King's Fund as a fundamental principle that should guide future strategic development within the NHS, with the potential to 


\section{Table 1. Solution-focused approach (SFA) toolkit.}

\section{Questions}

The coping question

How do you manage to go on? How did you cope until this point?

The continuation question

What ALREADY goes well that you want to continue?

The scaling question

Where are you now on a scale of 1-10? How did you get there from zero?

At your highest point - what was different?

The miracle question

So IF a miracle happened, what would be different?

What are your BEST hopes for the future?

The question predicting improvement

How will you KNOW things are better?

How will your dog/wife/child know things are better?

Identifying pre-encounter change

Even BEFORE you got here today, what improvements have you noticed?

Identifying recent progress

What's better since last time we met?

\section{Tasks}

Do something different

Notice when you overcome a bad habit

Notice exceptions

\section{Professional attitudes}

Listen with a constructive ear

Redefine stability as change

Assume that you do not know

Predict that positive change will happen
What will happen when you try ... to see if this helps?

Notice what you did when you successfully overcame the urge to do that

What's DIFFERENT on an occasion when that problem seems easier?

Notice good intentions and effective use of resources

Identify the skills active when adapting to remain stable in a difficult situation Avoid making assumptions and let the patient find the answer

Reinforce by using 'when' rather than 'if', or 'will' rather than 'might' ensure truly patient-centred care, as well as greater satisfaction for clinicians and financial savings due to more efficient delivery. ${ }^{13}$

Presenting medicine as a means of helping the patient achieve a 'preferred future' allows a successful compromise to be reached, and is more likely to result in a plan that is genuinely patient centred. Investigations and treatment options then become tools with which to support the patients' 'best hopes' and gain their buy-in to the medical management plan. By rephrasing information in this way, SFA can be utilised in a brief focused intervention, as well as during a period of continuity where a longer-term relationship is established. In the latter situation, SFA can be used to shape behaviour and build on achievements over time; when used briefly it can act as a pivot to shift the focus towards a desirable short-term outcome. The case examples described here are taken from personal experience of using SFA in a variety of hospital settings.

\section{Case 1: The unrealistic demanding husband}

Continuation; listening with a constructive ear; redefining stability as change

$\mathrm{Mr} \mathrm{A}$ is an irate husband, demanding to know why more is not being done to help his wife. He spends every day at her bedside, continuing the care for which he has taken sole responsibility since her diagnosis with a progressive terminal neurological disease. The weekend on-call medical registrar arrives after an urgent bleep to find $\mathrm{Mr}$ A pacing up and down the ward, even more upset after the nurses explained that she has developed another aspiration pneumonia and deteriorated significantly overnight. Mrs A now has Cheyne-Stokes respiration and is unresponsive to voice, so there is an urgency to help her husband understand that she is dying if there is to be a hope of achieving a peaceful and dignified death. 'You can't let her die... Why have they let her get this bad? You've got to do something.'

Resisting an instinctive explanation of all the clinical treatment so far and why she has failed to respond, the medical registrar takes a mental step back to look at the bigger picture. A simple acknowledgement, 'Mr A, you've been fighting for her for so long haven't you ...', shifts the focus of the conversation with immediate effect as the doughnut comes into view: his fierce advocacy for his wife. Mr A stops pacing and sits down. His countenance goes from anger to grief, as he describes how much he loves her (the doughnut again), that he knows she has had enough and he can't bear to see her like this. In less than 90 seconds he has shifted from 'you've got to save her' to 'this is what she wants'.

The conversation that had at first seemed impossible then happens naturally, and end-of-life care can be discussed: 'You know what's important to her ... how can we keep her comfortable and dignified in her last hours? These are some of the things she might need ... what do you think she would want?' 


\section{Case 2: The self-discharger}

Identifying pre-encounter change; listening with a constructive ear; assuming that you do not know; the coping question; predicting positive change

Miss B is threatening to self-discharge from the medical assessment unit after waiting three hours without being seen. She has been rude to nursing staff and is demanding to see a doctor. The temptation to say 'Fine, let her go, one less to see' is strong. Instead the medical registrar opens a two-minute interaction with 'As you've made the effort to get here, let's see what we can do for you before you have to leave' (the doughnut) and books a chest radiograph. Once she is positively engaged, it is easy to ask later 'How did you manage to get here today with two young children?', and her frustration becomes understandable when she explains that she has left them with a friend in order to attend hospital; a brief admission is clearly her best hope for the immediate future. She goes on to give a social history of childhood abuse, absent family support and a strong desire to do the best for her children. By the time she has been assessed and discharged with appropriate follow-up, rapport and trust have been established that will hopefully promote similar positive engagement in the future. Miss B receives the care that she deserves and the interaction is considerably more satisfying on both sides than it initially promised to be.

\section{Case 3: The patient with unexplained fatigue}

The coping question; the continuation question; listening with a constructive ear; the miracle question; predicting positive change $\mathrm{Mrs} \mathrm{C}$ is 89 and attends general medical clinic with her 90 -yearold husband. Her GP describes persistent fatigue and dyspnoea but cardiorespiratory examination is unremarkable, and her case notes already contain normal echo, chest radiograph and other results. On questioning she describes chronic severe back pain on any movement; an MRI of the spine last month showed marked degenerative change. She complains bitterly about being housebound due to pain, lists all the things that she can no longer do and the many futile previous appointments with various healthcare professionals. She expresses particular frustration at the failure of several treatments due to unpleasant side effects, stating that she sees no point in trying anything else.

'How have you coped up until now?' (looking for the doughnut) and 'What is a good day like?' are questions that bring about a grudging admission that she can help her husband do the dishes and other small tasks (there is the doughnut). 'If we could make everything better, what would you want to be doing?' follows on easily from this and establishes that she would like to go to church and the theatre again: these are her hopes for the future. Her manner gradually changes as she begins to ask questions and eventually even makes suggestions herself. After a full assessment and discussion of options, offering medicine as a tool that will help get her back to church and theatre going, she agrees with conviction to try a new regimen of simple analgesia and laxative cover. Mrs C asks for written instructions of how to start and alter this plan depending on response. She walks out of hospital with a smile and a word of thanks to the relieved medical registrar.

\section{Case 4: The patient refusing NIV}

Assume that you don't know; listening with a constructive ear-noticing good use of resources; predicting positive change; continuation of positive behaviour

Mrs D has been admitted to the accident and emergency department (A\&E) after her neighbour called an ambulance. She is acutely breathless due to an exacerbation of her chronic obstructive pulmonary disease (COPD), and blood gases after initial treatment have shown type 2 respiratory failure requiring non-invasive ventilation (NIV). However, she is refusing any further treatment and asking to go home, despite being told by A\&E staff of the serious nature of her condition and that she could rapidly deteriorate further. The medical registrar is called down to decide what should happen next.

It quickly becomes evident from talking to her that she understands the risks of refusing treatment, but the medical registrar feels that it would be wrong to accept this decision without further attempts to persuade her to accept the potentially life-saving treatment. A quick appraisal of what is known so far indicates that Mrs D is a fiercely independent woman, accustomed to looking after herself and not a usual attender at hospital. The medical registrar affirms Mrs D's need to protect her independence and acknowledges the frightening prospect of a hospital admission: 'You were brave in calling for help ... it must be especially hard when you are used to looking after yourself.' This opens up a route to the doughnut, which in this case is the very fact that she is currently in hospital and can be looked after: 'I am going to help you get back to your own home and be independent again as soon as possible.' Her positive response to this allows the medical registrar to explain the actions that can be taken to improve her breathing in order to move towards this - using medicine to help achieve her preferred future. Breaking it down into smaller steps makes the situation more manageable for both parties and so compromise is reached: Mrs D agrees to be transferred to the ward for nebulisers and steroids, and for her clinical response to this to be reassessed in an hour before further treatment is chosen.

\section{Solution-focused approach for personal use}

It can be easy to miss the doughnut altogether and focus on the 'hole' of unmanageable workload, never-ending training requirements and negative effects on one's personal life that are associated with this stage in a hospital medical career. Looking for existing strengths and building on these is a simple strategy to shape more productive behaviour and reduce energy spent in negative thought and behaviour patterns. It is an especially useful coping mechanism when feeling overwhelmed and short of time, encouraging a shift from a focus on problems to a focus on opportunities.

\section{Case 5: The weekend on call}

Avoiding assumptions; notice exceptions; do something different; continuation of positive behaviour

Friday morning looms. Three long days ahead of constant interruptions, hassle from bed managers and an inevitable afternoon pile-up of medical admissions. The core medical trainee (CMT) doctor working lacks confidence, often seeking reassurance and generally needing more supervision with 
management plans. Driving to work, the medical registrar contemplates why some weekends on call are less onerous than others, and what makes them more enjoyable (here comes the doughnut). A game plan takes shape in the registrar's mind, including proactive discussions about patients rather than waiting to be called, organising the team to take a break together later in the day and promising at the outset to complete at least one workplace-based assessment for everyone each day.

These prove surprisingly easy to achieve and result in a much better team dynamic than during previous weekends. The CMT doctor becomes more relaxed and articulate by the end of the day, contrary to the usual effect of 13 hours on call. The medical registrar attributes this to establishing more open and relaxed communication; a later conversation reinforces this when the CMT doctor describes how she had felt intimidated by the registrar's perceived superior knowledge. This provides an opening to share experiences of feeling out of depth, further encouraging her to confide her own gaps in knowledge, and resulting in a constructive workplace-based assessment with an action plan of targeted reading, as well as discussion about the human factors involved in performing well during an on-call.

\section{Conclusion}

Identifying best hopes for the future, establishing current strengths and then building on these are the cornerstones to a solution-focused approach. This is one way of finding a path through challenging doctor-patient interactions that can lead to a more rewarding experience as a medical registrar.

\section{References}

1 Royal College of Physicians. The medical registrar: Empowering the unsung heroes of patient care. London: RCP, 2013. www.rcplondon. ac.uk/projects/medical-registrar-empowering-unsung-heroespatient-care [Accessed 4 August 2014].
2 Chauduri E, Mason NC, Newbery N, Goddard AF. Career choices of junior doctors: is the physician an endangered species? Clin Med 2013;13:330-5.

3 Bray D, Groves K. A tailor-made psychological approach to palliative care. Eur J Palliat Care 2007;14:141-3.

4 de Shazer S, Berg I K, Lipchik E et al. Brief therapy: Focused solution-development. Family Process 1986;25:207-22.

5 Lipchik E, Derks J, LaCourt M, Nunnally E. The evolution of solution-focused brief therapy. In: Franklin C, Trepper TS, Gingerich WJ, McCollum EE (eds), Solution-focused brief therapy: A handbook of evidence-based practice. New York: Oxford University Press, 2012;3-19.

6 Visser CF. The origin of the solution-focused approach. Int J Sol Foc Prac 2013;1:10-17.

7 Gingrich WJ, Peterson LT. Effectiveness of solution-focused brief therapy: a systematic qualitative review of controlled outcome studies. Res Soc Work Prac 2013;23:266-83.

8 Viner RM, Christie D, Taylor V, Hey S. Motivational/solutionfocused intervention improves $\mathrm{HbAlc}$ in adolescents with Type 1 diabetes: A pilot study. Diabet Med 2003;20:739-42.

9 Vogelaar L, van't Spijker A, Vogelaar T et al. Solution focused therapy: A promising new tool in the management of fatigue in Crohn's disease patients. J Crohn's Colitis 2011;5:585-91.

10 Ingersoll-Dayton B, Schroepfer T, Pryce J. The effectiveness of a solution-focused approach for problem behaviors among nursing home residents. J Geront Soc Work 1999;32:49-64.

11 de Shazer S, Dolan Y, Korman H et al. More than miracles: The state of the art of solution-focused brief therapy. New York: Haworth Press, 2007.

12 Franklin C, Trepper TS, Gingerich WJ, McCollum EE (eds), Solutionfocused brief therapy: A handbook of evidence-based practice. New York: Oxford University Press, 2012.

13 Mulley A, Trimble C, Elwyn G. Patients' preferences matter. London: The King's Fund, 2012.

Address for correspondence: Dr S Blayney, Medicine for the Elderly, Southport and Ormskirk Hospital NHS Trust, Town Lane, Kew, Southport, Merseyside PR8 6PN.

Email: sarahblayney@doctors.org.uk

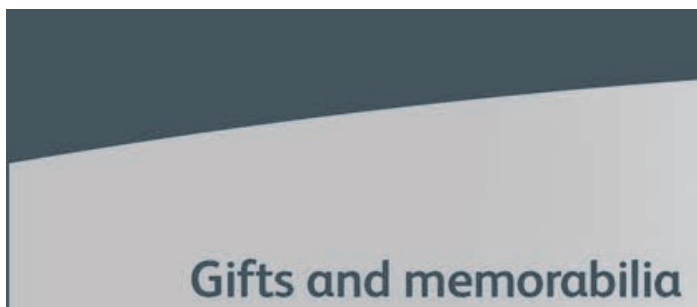

A new range of gifts based on a huge collection of art, and artifacts housed at the RCP's home in Regent's Park.

Elizabeth Garrett Anderson bag Large jute bag reinforced with a synthetic lining and short padded handles.

$£ 10.00$ (inc p+p)

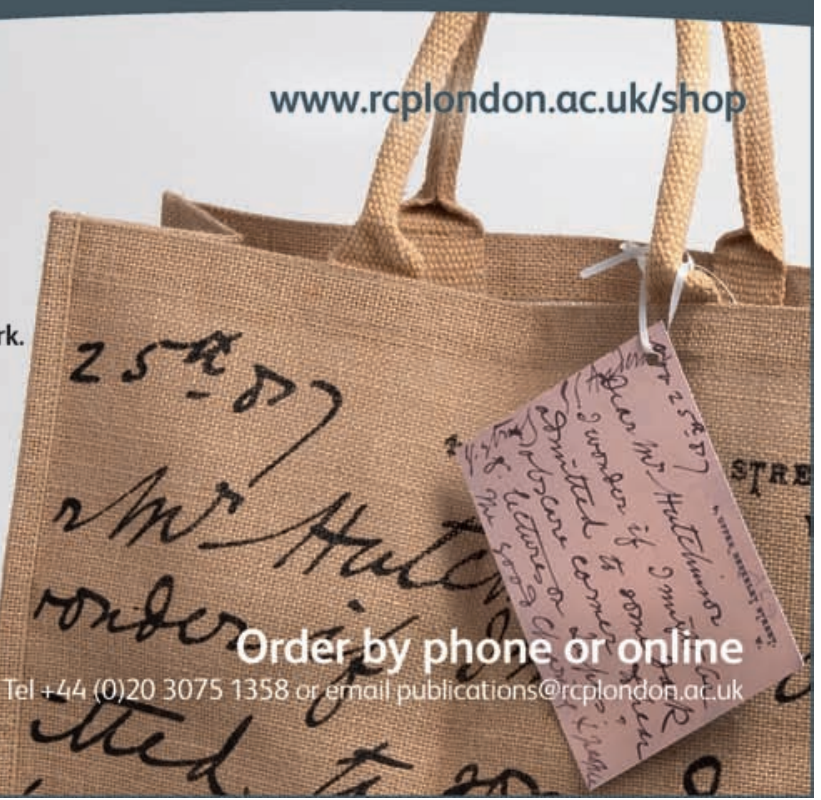

